CARTA AL DIRECTOR

\title{
LA LEY DE LA DEPENDENCIA SE HUNDE
}

\author{
Francisca Bernal Pérez.
}

Enfermera Hospital de Bellvitge. Hospitalet de Llobregat.

E-mail: paquibernal@gmx.es

Tras una noticia aparecida en el periódico ${ }^{(1)}$ sobre los recortes en la Ley de Dependencia, el ciudadano se ve en la obligación moral de decir: iYA BASTA!. No contento el gobierno con entresacar las entrañas a los funcionarios, ahora se va a cebar con La Ley de la Dependencia y sus beneficiarios. Nuestro gobierno se ha puesto a pensar y aduce que esta ley es insostenible por el cuantioso gasto que de ella se deriva.

Esta ley que fue aprobada en el año 2007 bajo mandato del gobierno socialista se constituyó como cuarto pilar del Estado del Bienestar y este pilar hoy en día se está desmoronando como una baraja de naipes.

Según las fuentes de este periódico, en este período más de 741.000 personas en España reciben actualmente una prestación o servicio de la Ley de la Dependencia y otras 312.000 están a la espera de ser atendidas, de ellas 165.000 son dependientes moderados.

Esta moratoria planteada por el Gobierno de la nación alude que durante el año 2012 no se podrá aspirar a recibir una prestación los dependientes en grado moderado. Será a partir del 2013 cuando se podrán incluir nuevos 
"beneficiarios" pero sin precisar el grado de discapacidad.

Con todas estas medidas económicas se pretende ahorrar 100 millones de euros, cuando el presupuesto total anual es de 6000 millones para esta Ley.

No hay dinero para nuestros mayores, son muchos y no son productivos, por lo que supongo que serán las familias las que aporten todos los gastos de sus cuidados. Esto no supondría ningún inconveniente si estas familias tuviesen una economía saneada, pero con casi cinco millones de parados, dudo mucho que ésta sea la situación.

Si los mayores no perciben las ayudas económicas prometidas por su gobierno ¿cómo podrán vivir dignamente?.

Estamos creando una sociedad en la que el trabajo lo es todo; nuestros mayores quedaron aparcados en otra dimensión, la solitud. Las familias sólo se reúnen en Navidad, el resto del año no hay tiempo.

Estas ayudas valían para que los cuidadores informales, la mayoría inmigrantes les hicieran la vida más soportable, al mismo tiempo creando puestos de trabajo para estas personas. Ahora la situación ha cambiado, serán las familias las que aporten toda la carga económica ya depauperada de por sí, para mantener al anciano en las mejores condiciones.

Si aceptamos las condiciones impuestas por el gobierno pasarán dos cosas:

1. Las familias que tengan más poder económico, serán las que puedan mantener a sus familiares en las mejores condiciones, las demás tendrán que realizar un sacrificio todavía no cuantificado.

2. Habrán muchos mayores que no aguantarán esta maniobra y quedarán varados en el camino. Sus pensiones no son grandilocuentes, por lo que estarán a merced de la caridad del Estado.

De todo lo expuesto se deduce que para ahorrar 100 millones de euros 
tienen que sufrir 165.000 personas y las que vengan detrás en las mismas condiciones. Hoy en día ser dependiente moderado está abocado a recibir la ingratitud de su país. Cuando más necesitamos la ayuda de nuestro Estado del Bienestar es cuando se nos cierran las puertas.

No soy política, pero creo que se pueden hacer muchas cábalas con los presupuestos y conseguir estas cantidades que no son tan astronómicas. Si no luchamos ahora, que nos deparará el futuro. Nosotros somos jóvenes ahora pero seremos mayores mañana.

Bibliografía:

1. Charo Nogueira. Una moratoria deja sin ayuda a más de 150.000 dependientes leves.

Disponible en http://elpais.com/diario/2011/12/31/españa/1325286012 850215.html consultado el 10-01-2012. 